\title{
Preparation and Comparative Study of Aerogels Based on Cellulose Nanocrystals and Nanofibers from Eucalyptus Pulp
}

\section{Wenkai Zhu}

Nanjing Forestry University

\section{Yang Zhang}

Nanjing Forestry University

\section{Xiaoyu Wang}

Huaiyin Normal University

\section{Yan Wu}

Nanjing Forestry University

\section{Minsu Han}

Yonsei University

\section{Jungmok You}

Kyung Hee University

Chong Jia

Nanjing Forestry University

Jeonghun Kim ( $\boldsymbol{Q}$ jhkim03@yonsei.ac.kr)

Yonsei University https://orcid.org/0000-0001-6325-0507

\section{Research Article}

Keywords: Nanocellulose, Aerogel, Nanocrystals, Nanofibers, Cross-linking, Eucalyptus pulp

Posted Date: November 1st, 2021

DOI: https://doi.org/10.21203/rs.3.rs-1005528/v1

License: (1) (1) This work is licensed under a Creative Commons Attribution 4.0 International License. Read Full License 


\section{Abstract}

Nanocellulose-based materials have attracted significant attention because of their attractive advantages. Particularly, aerogel, a porous nanocellulose material, have been used in diverse applications owing to their unique properties. In this study, short rod-like cellulose nanocrystals (CNCs) and long filament-like cellulose nanofibers (CNFs) were isolated from a eucalyptus pulp source using acidolysis and oxidation/mechanical methods, respectively. Subsequently, two different aerogels were prepared from the CNCs and CNFs using the sol-gel method and their properties were compared. The morphology, chemical structure, chemical composition, shrinkage rate, internal structure, thermal degradation, biophysical properties, and mechanical properties of the as-prepared aerogels were compared. Furthermore, the shrinkage of the CNC and CNF aerogels was effectively controlled using a supercritical $\mathrm{CO}_{2}$ drying process. Additionally, three decomposition regions were observed in the thermogravimetric analysis curves of the aerogels; however, the CNF aerogels exhibited enhanced thermal stability than the CNC aerogels. Further, the CNC and CNF aerogels exhibited a mesoporous structure, and the compressive strength of the CNC and CNF aerogels under $85 \%$ strain was 269.5 and $299.5 \mathrm{KPa}$, respectively. This study provides fundamental knowledge on the fabrication of CNCs, CNFs, and corresponding aerogels from lignocellulosic biomass, and their characteristics.

\section{Introduction}

Cellulose nanomaterials, such as cellulose nanofibers (CNFs), cellulose nanocrystals (CNCs), 2,6,6tetramethylpiperidine-1-oxy-oxidized cellulose nanofibers (TEMPO-CNFs), and other derivatives have received significant attention as a next-generation nanomaterial because of their abundancy, good biocompatibility, good chemical/physical properties, degradability, low-cost, large-scale production, and diverse use for composite materials (Dai et al. 2017; Khan et al. 2018; Kim et al. 2018; Kim et al. 2019; Du et al. 2019; Kim et al. 2020). Different treatment processes, which initiate degradation reactions, are used to break the glycosidic bonds in cellulose macromolecules to obtain cellulose nanoparticles with a onedimensional size ranging from 1-100 nm. Based on the methods used to degrade lignocellulosic biomass, the types of prepared nanocellulose materials are classified as highly-crystalline rod-like CNCs (4-25 nm in diameter, 100-500 nm in length) and longer fiber-like CNFs (5-30 nm in diameter, 300-5000 $\mathrm{nm}$ in length) (Chen et al. 2020; Nagarajan et al. 2021). Cellulose nanomaterials exhibit attractive properties, such as light-weight, high surface area, good mechanical strength, hydrophilicity, and available surface modifications (Klemm et al. 2011; Thomas et al. 2018). Owing to their excellent properties, cellulose nanomaterials have been used in various applications, such as food packaging, sensors, energy storage systems, environmental purification, and industrial materials (Kwon et al. 2020; Song et al. 2021; Kim et al. 2021; Mautner 2020; Tran et al. 2020).

Aerogel, which was first successfully produced by Kistler in 1931, is known as one of the lightest solids in the world, and has been used in various fields owing to their high porosity, high specific surface area, low density, low dielectric constant, and good adsorption (Shang et al. 2019; Pierre and Pajonk 2002; Wei et al. 2020). Recently, various aerogel types based on organics materials, polymers, silica, carbons, metal 
oxides, metals, and organic/inorganic hybrid materials have been prepared (Li et al. 2021; Li et al. 2019; Wang et al. 2020).

Nanocellulose, a natural polymer, has been applied for synthesis of aerogel, and it exhibits the characteristics of both traditional aerogels and cellulose, such as renewability, ultralight weight, biodegradability, low cost, and non-toxicity (Wan et al. 2019; Ahankari et al. 2021). Consequently, nanocellulose-based aerogels have emerged as the third-generation aerogel materials after inorganic and organic polymer aerogels. The common nanocellulose-based aerogels are classified as CNC and CNF aerogels. In addition, the size, morphology, crystallinity, and surface properties of CNC and CNF affect the properties of their corresponding nanocellulose-based aerogels.

Generally, CNC and CNF aerogels are fabricated using the sol-gel method to obtain cross-linked hydrogels, after which the cross-linked hydrogels are subjected to a drying process to obtain aerogels with a threedimensional (3D) space lattice. Previous studies have revealed that the synthesis process and raw material affect the properties of nanocellulose aerogels (Zhu et al. 2020; Sun et al. 2021). Owing to the significant potential application of nanocellulose-based aerogels in various high-value products, research on their preparation process is relatively mature (Kargarzadeh et al. 2018). However, the long preparation cycle, poor reproducibility, and equipment requirement of nanocellulose-based aerogel have restricted their effective application. For example, the solvent replacement stage during the preparation process of nanocellulose-based aerogels is time-consuming and labor-intensive, and requires a large amount of alcohols. Therefore, it is important to develop alternative preparation process that can not only reduce the preparation time of aerogels but also reduce the preparation cost and enable commercialization (Gong et al. 2021; Jiang et al. 2020).

Compared to traditional cellulose materials, CNCs and CNFs possess higher crystallinity and specific surface area; thus, enabling the formation of aerogels with good mechanical stability and excellent selfassembly structure (Zhang et al. 2018; He et al. 2021). CNCs are rod-like crystals with high crystallinity, large rigidity, and a small length:diameter ratio (Habibi et al. 2010). In contrast, CNFs have a flexible fiber structure with a lower crystallinity than CNCs (Xu et al. 2020; Rol et al. 2019). Under a weak interaction force, CNCs and CNFs can spontaneously assemble to form aerogels with a 3D network porous structure. Particularly, the abundant hydroxyl groups in the CNCs and CNFs chains provide favorable conditions for the chemical cross-linking of aerogels with its skeleton structures. Various studies have investigated the use of various lignocellulosic biomass for the preparation of CNC and CNF aerogels (Wang et al. 2016; Wang et al. 2020; Zhang et al. 2018). However, owing to the high crystallinity of CNCs, the prepared CNCbased aerogels are susceptible to deformation. In contrast, CNF aerogels exhibit excellent flexibility and resistance to compression deformation, which depends on the high aspect ratio and specific surface area of CNFs (De et al. 2017; Lv et al. 2019). However, the 3D reticulated aerogels formed by the entanglement of the irregular flexible filamentous fibers of CNFs are susceptible to irreversible deformation under external force, resulting in the loss of its porous structure. This can be attributed to the weak intermolecular force and hydrogen bonding force of CNFs, which limit their ability to withstand stress ( $\mathrm{Li}$ et al. 2018, Budtova 2019). Moreover, related studies have been carried out on the preparation of 
nanocellulose aerogels using different raw materials and methods (Chen et al. 2014; Shamskar et al. 2019; Dong et al. 2021). However, to the best of our knowledge, there are no studies on the comparison of the performance of CNC and CNF aerogels prepared from the same raw material.

In this study, CNC and CNF suspensions were extracted from eucalyptus pulp, which was used as the raw material source, using sulfuric acid hydrolysis and oxidation/mechanical, respectively, and the suspensions were characterized. Subsequently, the corresponding CNC and CNF aerogels were prepared using the suspension titration method, salt solution induction method, and supercritical $\mathrm{CO}_{2}$ drying method. The chemical composition, shrinkage rate, internal structure, morphology, crystallinity, specific surface area, compression strength, and thermal stability of the aerogels were systematically compared. This study innovatively reveals the physical and chemical properties of CNC and CNF aerogels isolated from the same raw materials.

\section{Experimental}

\subsection{Materials}

Eucalyptus pulp was obtained from Nanjing Southeast Paper Mill (Nanjing China). Concentrated sulfuric acid ( $\geq 98 \%$ ), ethanol (99.5\%), tert-butyl alcohol (99.7\%), and calcium chloride $\left(\mathrm{CaCl}_{2}, \geq 98 \%\right)$ were purchased from Sinopharm Chemical Reagent Co., Ltd. (Shanghai, China). Ammonium persulphate $\left(\left(\mathrm{NH}_{4}\right)_{2} \mathrm{~S}_{2} \mathrm{O}_{8}, 99.5 \%\right)$ and potassium hydroxide $(\mathrm{KOH}, 99 \%)$ were supplied by Nanjing Chemical Reagent Co., Ltd. (Nanjing, China). Liquid carbon dioxide used in the supercritical $\mathrm{CO}_{2}$ drying process was purchased from Nanjing Special Gas Co., Ltd. (Nanjing, China). All chemicals were reagent grade, and were used as received without further purification.

\subsection{Fabrication of CNC and CNF aerogels}

Two different types of nanocelluloses (CNCs and CNFs) were prepared from eucalyptus pulp using sulfuric acid hydrolysis and ammonium sulfite oxidation/mechanical, respectively (the specific preparation methods are described in the Supporting Information). Subsequently, the corresponding nanocellulose aerogels were prepared using a simple and facile sol-gel method and supercritical $\mathrm{CO}_{2}$ drying, as described below (Fig. 1). Briefly, nanocellulose suspensions with mass fractions of 1.5, 2.5 and $3.5 \%$ were formulated using the as-prepared CNC and CNF suspension solutions. Subsequently, the suspensions were ultrasonicated for $15 \mathrm{~min}$ in an ice bath environment to obtain a well-dispersed solution, after which the solution was left stationary at room temperature for $60 \mathrm{~min}$. Thereafter, the obtained nanocellulose was gradually dropped into $\mathrm{CaCl}_{2}$ solution $(0.25 \mathrm{~mol} / \mathrm{L})$ using a medical glass syringe to form a spherical hydrogel, after which the hydrogel was left for $48 \mathrm{~h}$ to obtain fully gelled hydrogel particles. Subsequently, the water in nanocellulose hydrogel was replaced with an alcohol using the solvent replacement method. First, the nanocellulose hydrogels were immersed in a tert-butanol solution (25 wt\%), and the mass fraction of tert-butanol solution was changed every $12 \mathrm{~h}(50,75$ and $100 \%$, respectively) to obtain spherical nanocellulose alcohol gels. Lastly, the nanocellulose alcohol gel 
was subjected to supercritical $\mathrm{CO}_{2}$ drying using an SFT-105 supercritical extractor (SepTech Co., Ltd., USA) (Supporting Information). Nanocellulose aerogels with different concentrations were obtained and denoted as $\mathrm{X}$-CNC aerogels and $\mathrm{X}$-CNF aerogels $(\mathrm{X}=1.5,2.5$, and $3.5 \%)$.

\subsection{Characterization}

The functional groups of the samples were investigated using Fourier transform-infrared spectroscopy (FT-IR, VERTEX-80V, Bruker, Germany). The FT-IR spectra of samples were obtained in the range from 4000 to $500 \mathrm{~cm}^{-1}$ at a resolution of $4 \mathrm{~cm}^{-1}$.

The surface morphology of the well-dispersed CNCs and CNFs was investigated using transmission electron microscopy (TEM, JEM-2100F, JEOL Ltd., Tokyo, Japan) at an acceleration voltage of $75 \mathrm{kV}$. The morphology and microstructure of the CNC and CNF aerogels with different concentration were investigated using scanning electron microscopy (SEM, AJSE-7600, JEOL Ltd., Tokyo, Japan) at an accelerating voltage of $10 \mathrm{kV}$.

To investigate the size distribution of the CNCs and CNFs, the pore size of 150 nanocelluloses in at least 20 randomly selected TEM images was measured using an Image-Pro Plus 6.0 software (Media Cybernetics, Inc., Rockville, MD, USA).

The surface charge on the eucalyptus pulp, CNCs, and CNFs were confirmed using a Zetasizer Nano ZS (Malvern Instruments Ltd., UK).

$\mathrm{N}_{2}$ adsorption/desorption isotherms of the CNC and CNF aerogels were obtained using an ASAP 2020 Analyzer (Micromeritics Ltd., USA) at $77 \mathrm{~K}$. Thermogravimetric analysis (TGA) and differential thermogravimetric (DTG) analysis of the aerogel samples were performed using Pyris 1 (TGA, PerkinElmer Cetus Instruments, USA). The chemical state and composition of the CNC and CNF aerogels were determined using X-ray photoelectron spectroscopy (XPS, AXIS Ultra DLD spectrometer, Kratos Analytical Ltd., UK). X-ray diffraction (XRD) patterns of the samples were obtained using an X-ray diffractometer (Ultima IV, Rigaku, Japan) with Cu Ka radiation at a step rate of $5^{\circ} \mathrm{min}^{-1}$ recorded in the range from 10 to $80^{\circ}$, operating at $30 \mathrm{kV}$ and $40 \mathrm{~mA}$. The crystallinity indices ( $\mathrm{Cr} /$ ) of the CNCs and CNFs prepared from eucalyptus pulp were estimated and calculated using the Turley calculation:

$$
\operatorname{Cr} I=\frac{I_{002}-I_{a m}}{I_{002}} \times 100 \%
$$

where $\mathrm{Cr}$ is the crystallinity index (\%) of the sample, $I_{002}$ is the extreme intensity of the (002) lattice diffraction angle, and $l_{a m}$ is the scattering intensity of the non-crystalline background diffraction at minimum in intensity near $18^{\circ}$. 
The yields of the acidolysis and oxidation/mechanical treatment for CNC and CNF were calculated using the following equation:

$$
Y=N \frac{m_{1}}{m_{0}} \times 100 \%
$$

where $Y$ and $N$ represent the yields of nanocellulose and nanocellulose content in suspension respectively; $m_{1}$ and $m_{0}$ are the mass of the suspension and eucalyptus pulp, respectively.

The density, drying shrinkage, and porosity of the two types of nanocellulose aerogels were calculated using equations (3), (4), and (5), respectively. The specific method and steps are discussed in the supporting information.

$$
\begin{aligned}
& \rho_{\text {aerogels }}=\frac{M_{\text {aerogels }}}{V_{\text {aerogels }}} \\
& S=\frac{\left(L_{0}-L_{C}\right)}{L_{0}} \times 100 \% \\
& \varepsilon=\left(1-\frac{\rho_{\text {aerogels }}}{\rho_{s}}\right) \times 100 \%
\end{aligned}
$$

where $\rho_{\text {aeroge/s }} M_{\text {aeroge/s }}$ and $V_{\text {aerogels }}$ are the volumetric mass densities, weight, and volume of nanocellulose aerogels, respectively. $S, L_{0}$, and $L_{C}$ are the shrinkage, maximum average size of the alcohol gels, and average longest diameter of the aerogels, respectively. $\varepsilon$ is the porosity of the aerogels and $\rho_{s}\left(1.56 \mathrm{~g} / \mathrm{cm}^{3}\right.$ at here) is the bulk density of cellulose (Liu et al. 2018).

The compression properties of the aerogels with different concentrations prepared under the optimal drying process were investigated using a universal mechanical testing machine (CMT-4204, Shanghai Xieqiang Instrument Technology Co., Ltd., Shanghai, China). To investigate the mechanical properties, the nanocellulose aerogels were made into cylinders. The test was performed at a compression speed of 1 $\mathrm{mm} \mathrm{min}{ }^{-1}$, and the sample was compressed to $90 \%$ of its initial diameter, after which the compression was stopped.

\section{Results And Discussion}

\subsection{Characterization of CNCs and CNFs}

Figure S1-2 show the flow diagram of the extraction of CNCs and CNFs from eucalyptus pulp. Briefly, the glycosidic bonds in the amorphous regions of eucalyptus pulp fibers were broken using chemical and 
chemical/mechanical methods. Subsequently, the amorphous region was degraded and the highly crystalline CNCs and CNFs were extracted from the crystalline region (Fig. 2a). The strong acid treatment facilitated the breaking down of the hydrogen bonds within the pulp fiber molecules to obtain short rodlike CNCs (Zhu et al. 2020). In contrast, the oxidation and mechanical treatment broke down the hydrogen bonds between pulp fiber molecules to obtain long cellulose-like CNFs (Sun et al. 2020). Therefore, two nanocellulose with different morphologies were obtained by treating eucalyptus pulp with different methods. In addition, the yield of CNCs was lower than that of CNFs (Table 1).

The as-prepared CNCs and CNFs were characterized using FT-IR, TEM, XRD, zeta potential, and grainsize analysis, and the results are shown in Fig. 2. The surface morphology and particle size distribution of the samples in the figures confirmed the successful preparation of CNCs and CNFs via the chemical and oxidation/mechanical treatments, respectively. In addition, the diameter and length of the as-prepared short rod-like CNCs were 10-50 and 100-200 nm, respectively, and the length-to-diameter ratio (aspect ratio) was between 10-15 (Fig. $2 \mathrm{~b}$ and c). Furthermore, no significant agglomeration phenomenon was observed in the CNCs solution, indicating the good dispersion effect of the CNCs obtained using sulfuric acid hydrolysis method. Additionally, the prepared CNCs exhibited a uniform dispersion, with a neat structure and homogeneous morphology. The CNFs obtained by the chemical pretreatment and mechanical grinding of eucalyptus pulp exhibited a milky white color. TEM images revealed that the CNFs exhibited an interwoven filament shape, with a notable agglomeration phenomenon (Fig. 2e). This agglomeration effect can be attributed to the interweaving of the CNF fibers via hydrogen bond owing to the existence of a large number of hydroxyl groups during the fibrillation process of eucalyptus pulp. The diameter and length of the filament-like CNFs was mostly in the range of 50-70 nm and 1-2 $\mu \mathrm{m}$, respectively, with an aspect ratio of 15-40 (Fig. 2f). The zeta-potential values at the CNCs and CNFs surface were -36.4 and $-32.1 \mathrm{mV}$ (Table 1), indicating the presence of carboxyl groups, which was conducive to self-assembly to form gels.

To investigate the effect of the chemical and mechanochemical treatment on the crystal structure of eucalyptus pulp, the crystallinity of the eucalyptus pulp, CNCs, and CNFs was investigated using XRD (Fig.2d and g,Table 1). The XRD patterns of the eucalyptus pulp, CNCs, and CNFs were similar to that of natural cellulose I. In addition, their main diffraction peaks were located at $2 \theta=15.5,22$, and $34.5^{\circ}$, which corresponded to the (10), (002), and (040) diffraction planes, respectively (Nishiyama et al. 2010). Furthermore, the XRD analysis revealed that the chemical and oxidation/mechanical methods had no effect on the crystal structure of CNCs and CNFs obtained from eucalyptus pulp, and the crystals of CNCs and CNFs were all cellulose type I crystals. The presence of the type I cellulose structures enabled the subsequent synthesis of high-performance nanocellulose aerogels (Lee et al. 2021). Based on the Turley formula, the crystallinity of the CNCs and CNFs were $47.73 \%$ and $28.18 \%$ higher than that of eucalyptus pulp, respectively. This could be attributed to the irregular arrangement and non-orientation of the amorphous region of pulp cellulose, which increased the susceptibility of the non-crystalline region to sulfonation reaction, resulting in the degradation of the non-crystalline region. In contrast, owing to the regular and compact structure of the crystalline region of cellulose, it was not easily destroyed by the treatments and the structure was retained; thus, the crystallinity of the produced nanocellulose was 
higher than that of the raw material. However, some previous studies have reported that a change in reaction conditions leads to the excessive hydrolysis of nanocellulose, resulting in a decrease in crystallinity (Sun et al. 2016).

Table 1

Relative crystallinity, zeta potential, and yield of the raw materials and the two prepared nanocellulose samples.

\begin{tabular}{|lcclcc|}
\hline Samples & $I_{\text {oo2 }}$ & $I_{a m}$ & Relative crystallinity (\%) & Zeta potential values (mV) & Yield (\%) \\
\hline Eucalyptus pulp & 2128 & 931 & 56.25 & -15.7 & $/$ \\
CNCs & 5504 & 930 & 83.1 & -36.4 & 42.6 \\
\hline CNFs & 3384 & 944 & 72.1 & -32.1 & 55.4 \\
\hline
\end{tabular}

This indicates that the proper control of the reaction condition is essential for protecting the crystallization zone of nanocellulose.

\subsection{Changes in the chemical composition}

The characteristic functional group, chemical structure, and chemical composition of the pulp, CNCs, CNFs, and their corresponding aerogels were investigated using FT-IR and XPS. The characteristics absorption peaks of CNC aerogels and CNF aerogels were observed at approximately 3425, 2900, 1635 , 1430,1370 , and $900 \mathrm{~cm}^{-1}$ (Fig. 3a and b). In addition, all the samples exhibited the characteristic absorption peaks of cellulose type $\mathrm{I}$, and were consistent with those of the raw material. This indicates that the aerogel exhibited similar crystal structures and maintained the $I_{\beta}$ type crystal structure of cellulose (Hult et al. 2000). Additionally, this indicates that the ultrasound, salt solution, and supercritical drying processes did not induce any chemical reaction in the CNCs and CNFs solutions. Thus, these results suggest that the entire nanocellulose aerogel formation process was a physical gelation process. In addition, both aerogels exhibited a wide absorption peak in the range of $3000-3700 \mathrm{~cm}^{-1}$, which could be attributed to formation of hydrogen bonds between and within the nanocellulose molecules. Furthermore, the $\mathrm{O}-\mathrm{H}$ bonds in these hydrogen bonds generated stretching vibrations and superposed each other under the association effect. In addition, additional absorption peaks were observed at 2900 and $1635 \mathrm{~cm}^{-1}$ in the FT-IR spectra of the aerogels, which corresponded to the $\mathrm{C}-\mathrm{H}$ bond in $-\mathrm{CH}_{2}-$ and the $-\mathrm{OH}$ group in the water molecule adsorbed by hydrophilic group in the nanocellulose molecule, respectively. Furthermore, additional peaks were observed at 1430 and $1370 \mathrm{~cm}^{-1}$, which corresponded to the shear vibration peaks generated by $-\mathrm{CH}_{2}$ at $\mathrm{C}-6$ in the cellulose molecule and the bending vibration peak generated by $\mathrm{C}-\mathrm{H}$, respectively. In addition, sharp absorption peaks were observed at 1165 and 900 $\mathrm{cm}^{-1}$, which corresponded to the asymmetric vibration peak of $\mathrm{C}-\mathrm{O}-\mathrm{C}$ on $\mathrm{C}-6$ ring. Furthermore, the peak at $1062 \mathrm{~cm}^{-1}$ was ascribed to the stretching vibration peak of $\mathrm{C}-\mathrm{O}$ on $\mathrm{C}-6$ ring. The major absorption peaks of the nanocellulose aerogels are shown in Table S1 (Leung et al. 2011; Xu et al. 2013). 
Compared to the FT-IR spectrum of eucalyptus pulp, new characteristics peaks were observed in the FT-IR spectra of the CNC and CNF aerogels at 1205 and $1721 \mathrm{~cm}^{-1}$, which could be attributed to the different extraction methods of CNCs and CNFs solution (hydrolysis and oxidation methods). The peak at 1205 $\mathrm{cm}^{-1}$ in the FT-IR spectra of the CNC and CNC aerogel was ascribed to a new stretching vibration peak of $S=0$. This could be attributed to the esterification reaction between the secondary hydroxyl group of cellulose molecules and $\mathrm{SO}_{4}{ }^{2-}$ in sulfuric acid to generate cellulose sulphate during the hydrolysis of the pulp (Oh et al. 2005). Consequently, the addition of $\mathrm{SO}_{4}{ }^{2-}$ made the surface of $\mathrm{CNCs}$ negatively charged; thus, making the CNCs repel each other in the suspension, resulting a good dispersion. In addition, the new absorption peak at $1721 \mathrm{~cm}^{-1}$ was ascribed to the $\mathrm{C}=0$ stretching vibration peak in carboxyl group (Fig. 3b). The - O-O- in $\left(\mathrm{NH}_{4}\right)_{2} \mathrm{~S}_{2} \mathrm{O}_{8}$ is well known to be very unstable and easily decomposed into hydrogen peroxide and oxygen atoms with strong oxidizing properties under heating conditions. This enables the oxidation of the primary alcohol hydroxyl group in the cellulose molecule, leading to the formation of aldehyde or carboxyl group (Lu et al. 2020; Aminah et al. 2019).

The surface chemical structure of the CNC and CNF aerogels was investigated using XPS. The CNC and CNF aerogels were mainly composed of $C$ and $O$ (Fig. 3c-e and Table S2). The $C 1$ s and $O 1$ s peaks of the CNC and CNF aerogels were observed at binding energies of 532.44 and $286.04 \mathrm{eV}$, respectively. Furthermore, the C:O ratio of the CNF aerogel (1.18) was lower than that of the CNC aerogel (1.34) (Table S2). The decrease in the $O$ content may be attributed to the massive dehydration of cellulose during the hydrolysis process using sulfuric acid. The CNC and CNF aerogels exhibited similar high-resolution C $1 \mathrm{~s}$ spectra, indicating the similar skeleton and chemical structure of the aerogels. In addition, the peaks observed at $285.4,286$, and $286.7 \mathrm{eV}$ in the high-resolution $\mathrm{C} 1 \mathrm{~s}$ spectra of the aerogels were attributed to $\mathrm{C}-\mathrm{C}, \mathrm{C}-\mathrm{OH}$, and $\mathrm{C}-\mathrm{O}-\mathrm{C}$, respectively.

\subsection{Shrinkage rate of the nanocellulose aerogels}

Figure 4 shows the shrinkage diagram of the CNC and CNF aerogels and the effect of the supercritical $\mathrm{CO}_{2}$ drying process on the shrinkage rate of the aerogels. Among them, Fig. 4a shows the optical images of CNC and CNF suspensions with different concentrations. The drying process of nanocellulose aerogel involves the conversion of the wet gel into an aerogel via the replacement of tert-butyl alcohol in the pores of the alcohol gel network using a gas, as shown in Fig. 4b. The time, temperature, and pressure of the supercritical $\mathrm{CO}_{2}$ drying process had effects on the shrinkage rate of the $\mathrm{CNC}$ and $\mathrm{CNF}$ aerogels. The optimal conditions of the supercritical $\mathrm{CO}_{2}$ drying process and corresponding shrinkage data to obtain CNC and CNF aerogels are shown in Table S3. The drying shrinkage rate of the $1.5 \%-\mathrm{CNC}$ and CNF aerogels was significantly larger than those of the $2.5 \%$ - and $3.5 \%$-CNC and CNF aerogels under the same process conditions. This could be attributed to the fact that the number of hydrogen bonds formed during the gelation process increased with an increase in the number of nanocellulose per unit volume. Moreover, the strength of the aerogel network skeleton structure increased with a decrease in the mass fraction; thus, leading to a smaller shrinkage rate. Additionally, when the additional forces such as 
osmotic pressure, capillary force, water stress and separation stress causing shrinkage are balanced with the strength of the aerogel, the shrinkage rate will not change.

An increase in the drying time had no effect on the shrinkage rate of the CNC and CNF aerogels (Fig. 4c and $\mathrm{f}$ ). This indicates that the length of the drying time only determines the exchange between solute and solvent. The optimal drying temperatures of the CNC and CNF aerogels were 45 and $50^{\circ} \mathrm{C}$, respectively (Fig. $4 \mathrm{~d}$ and g). At a constant drying time and pressure, the shrinkage of the aerogels with different mass fractions decreased with increasing temperature. In addition, because the supercritical $\mathrm{CO}_{2}$ drying system gradually approaches supercritical state with increasing temperature, the surface tension produced during the drying process gradually decreased, resulting in a decrease in the shrinkage rate. The optimal drying pressures of the CNC and CNF aerogels were 12 and $13 \mathrm{MPa}$, respectively (Fig. $4 \mathrm{e}$ and $\mathrm{h}$ ). In addition, the shrinkage rate of the aerogels with different mass fractions decreased with increasing drying pressure.

\subsection{Internal structure and morphology of the nanocellulose aerogels}

To investigate the effects of the mass fraction of CNCs and CNFs on the morphology of the corresponding aerogels, the internal structure of the CNC and CNF aerogels were investigated using SEM. Fig. $5 a$ shows the fabrication mechanism and formation procedure of the CNC and CNF aerogels. The formation process of the aerogels can be summarized into two steps. First, CNCs and CNFs were crosslinked to form the corresponding alcohol gel using the sol-gel method. Thereafter, the CNCs and CNFs were placed in the tert-butyl alcohol for the cross-linking reaction. Subsequently, the porous CNC and CNF aerogels were prepared by sublimating the solvent solid phase in the cross-linked alcohol gel using the supercritical drying method. The nanocellulose molecules in the CNC and CNF aerogels mainly interacted and intertwined together via hydrogen bonding force (Fig. 5a).

Figure 5b-g show the internal structure morphology of the CNC and CNF aerogels with different mass fractions. The CNC and CNF aerogels were 3D network structures formed by the gaps between the corresponding nanocellulose molecules, with no collapse in their structure. This indicated that the hydroxyl groups between the nanocellulose formed hydrogen bonds and intertwined with each other, thus forming a 3D network structure (Li et al. 2018; Jiang et al. 2013). In addition, the drying process had no effect on the internal structure of the alcohol gel owing to the elimination of the tension at the gas-liquid interface by the supercritical $\mathrm{CO}_{2}$ drying process. This confirmed that the supercritical $\mathrm{CO}_{2}$ drying process is advantageous for obtaining CNC and CNF aerogels with excellent morphology. Furthermore, the mass fraction of the CNC and CNF aerogels affected their internal morphology. With an increase in the mass fraction of the CNC and CNF, the distance between molecules gradually decreased, resulting in smaller pores. In addition, some aggregation may occur to form a layered structure. At a mass fraction of $1.5 \%$, the pore structure of the CNC and CNF aerogels was very sparse. However, at a mass fraction of 2.5 and $3.5 \%$, the CNC and CNF aerogels exhibited a dense internal structure, with no notable difference between 
the two aerogels. These results indicate that the concentration of CNCs and CNFs only affects the density and pore size of the internal network structure of aerogels with no effect on their morphology.

\subsection{Thermal stability analysis}

The TGA and DTG curves of the original eucalyptus pulp, CNC, and CNF aerogels with different concentrations of the corresponding nanocellulose suspension are shown in Fig. 6 . The thermal degradation initial temperature $\left(\mathrm{T}_{i}\right)$, peak decomposition temperature $\left(\mathrm{T}_{\text {peak }}\right)$, and remaining residue of all the samples are listed in Table 2. The TG curves of the samples can be divided into three regions, which could be attributed to the inherent properties of woody biomass materials (Fig. 6a and c) (Zhu et al. 2019). The first thermal degradation stage occurred in the temperature range from $25-200^{\circ} \mathrm{C}$, which could be attributed to the overflow of a small amount of water and trace gas absorbed in the aerogels. In the second pyrolysis stage ranging from 200 to $400^{\circ} \mathrm{C}$, the aerogel exhibited a steep thermal degradation curve and a large weight loss, which accounted for about $85 \%$ of the total weight loss. This could be attributed to the dehydration decomposition and carbonization reaction of the sample in this stage, which resulted in the production of a large amount of water, gas, and other substances. The overflow of these substances resulted in a significant reduction in the weight of the samples. At temperatures higher than $400^{\circ} \mathrm{C}$, the thermal degradation residues of the aerogels were further decomposed into volatile gases, and the remaining solid carbonization gradually forms a graphite structure (Zhao et al. 2019).

The CNC and CNF aerogels exhibited an earlier degradation onset compared to the raw material. This could be attributed to the fact that the surface of the CNC and CNF obtained by the hydrolysis of sulfuric acid and ammonium persulfate oxidation, respectively, contains a certain amount of sulfonate groups, which decreased the thermal stability of the corresponding aerogels. Furthermore, compared to the eucalyptus pulp, the CNC and CNF aerogels exhibited a lower polymerization degree and higher specific surface area. The ratio of the reduced end on its surface to the exposed reactive group increased, thus resulting in a decrease in its thermal stability. Additionally, the thermal stability of the CNF aerogels was better than that of the CNC aerogels. In addition, owing to the higher aspect ratio of the CNF compared to that of the CNC, the maximum weightlessness rate of the CNC aerogels was lower than that of CNF. Particularly, the mass fraction of the CNC and CNF had a significant effect on the thermal stability of the CNC and CNF aerogels (Table 2 and Fig. $6 \mathrm{~b}$ and $\mathbf{d}$ ). The thermal stability of the aerogels increased with an increase in the mass fraction, which could be attributed to the fact that the cross-linking of nanocellulose molecules during the gelation process increased with an increase in the mass fraction; thus, resulting in the formation of more hydrogen bonds. Consequently, the energy required by the thermal degradation process to break these hydrogen bonds increased.

\subsection{Analysis of the $\mathrm{N}_{2}$ sorption isotherms and biophysical properties}

The porous property of the nanocellulose aerogels obtained under the optimal drying process was characterized using $\mathrm{N}_{2}$ adsorption-desorption test (Fig. 7). The CNC and CNF aerogels exhibited similar $\mathrm{N}_{2}$ adsorption isotherms. The CNC and CNF aerogels exhibited a type IV isotherm with a type H3 
hysteresis loop, based on the International Union of Pure and Applied Chemistry (IUPAC) classification (Fig. 7a and b). The high-pressure region from 0.8 to 1.0 demonstrates the existence of a mesoporous structure in the nanocellulose aerogels.

Table 2

Thermal properties of the eucalyptus pulp, CNC, and CNF aerogels at different concentrations under $\mathrm{N}_{2}$ atmosphere.

\begin{tabular}{|llllllll|}
\hline Samples & $\begin{array}{l}\text { Eucalyptus } \\
\text { pulp }\end{array}$ & $\begin{array}{l}1.5 \%- \\
\text { CNC } \\
\text { aerogel }\end{array}$ & $\begin{array}{l}2.5 \%- \\
\text { CNC } \\
\text { aerogel }\end{array}$ & $\begin{array}{l}\text { 3.5\%- } \\
\text { CNC } \\
\text { aerogel }\end{array}$ & $\begin{array}{l}\text { 1.5\%-CNF } \\
\text { aerogel }\end{array}$ & $\begin{array}{l}\text { 2.5\%-CNF } \\
\text { aerogel }\end{array}$ & $\begin{array}{l}\text { 3.5\%-CNF } \\
\text { aerogel }\end{array}$ \\
\hline$T_{i}\left({ }^{\circ} \mathrm{C}\right)$ & 265 & 196 & 200 & 211 & 204 & 210 & 215 \\
\hline $\begin{array}{l}T_{\text {peak }} \\
\left({ }^{\circ} \mathrm{C}\right)\end{array}$ & 364 & 261 & 265 & 271 & 342 & 344 & 350 \\
$\begin{array}{l}\text { Residue } \\
(\mathrm{wt} \%)\end{array}$ & 11.3 & 29.1 & 35.6 & 39.2 & 22.7 & 27.6 & 36.8 \\
$\begin{array}{l}\text { at } 600 \\
{ }^{\circ} \mathrm{C}\end{array}$ & & & & & & & \\
\hline
\end{tabular}

This confirms that the internal morphology of the CNC and CNF aerogels was composed of a mesoporous 3D network structure, which was formed by self-aggregation through hydrogen bonding. In the low-pressure region from 0 to 0.2 , the adsorption capacity of $\mathrm{N}_{2}$ increased sharply, indicating the existence of micropores. These results indicate that the prepared aerogels consisted of mesopores and macropores.

The pore-size distributions of the CNC and CNF aerogels were obtained using $\mathrm{N}_{2}$ adsorption-desorption isotherms and $\mathrm{BJH}$ equation, and the results are shown in Fig. $7 \mathrm{c}$ and $\mathbf{d}$. The results revealed that the density of the internal pore structure of the aerogels gradually increased and the pore size decreased with an increase in the nanocellulose mass fraction. At mass fractions of $1.5,2.5$, and $3.5 \%$, the average pore sizes of the CNC aerogels were approximately 45,33 , and $30 \mathrm{~nm}$, respectively. In addition, the average pore sizes of the CNF aerogels at mass fractions of $1.5,2.5$, and $3.5 \%$ were 33,23 , and $23 \mathrm{~nm}$, respectively. These results indicate that the two aerogels were majorly composed of mesopores with only a small amount of micropores. The pore size of the aerogels at mass fractions of 2.5 and $3.5 \%$ were similar.

The calculated specific surface area and porosity characteristics of the as-prepared CNC and CNF aerogels derived from the $\mathrm{N}_{2}$ adsorption-desorption isotherms are summarized in Table 3. The specific surface area and density of the as-prepared aerogel increased with an increase in the mass fraction of the corresponding nanocellulose, whereas the pore volume decreased. In addition, owing to the increase in nanocelluloses and hydroxyl groups, the 3D network structure of the as-prepared aerogels became more compact; thus increasing the $\mathrm{S}_{\mathrm{BET}}$ and reducing the pore volume of the aerogels. The density of the 
CNC and CNF aerogels increased with an increase in the concentration of the corresponding nanocellulose per unit volume.

\subsection{Mechanical strength}

Compared to conventional inorganic aerogels, the CNC and CNF aerogels exhibited high ductility and toughness. Fig. $8 \mathrm{a}$ and $\mathrm{b}$ show the compressive stress-strain curves of the CNC and CNF aerogels with different concentrations. The test results revealed that although the aerogels were exceedingly soft, it exhibited a certain degree of toughness. The compressive stress of the CNC and CNF aerogels increased gradually before compressive strain of $80 \%$,

Table 3

Specific surface area, pore volume, density, and porosity of the CNC and CNF aerogels.

\begin{tabular}{|lllll|}
\hline Samples & Specific surface area $\left(\mathrm{m}^{2} / \mathrm{g}\right)$ & $\mathrm{V}_{\text {pore }}\left(\mathrm{cm}^{3} / \mathrm{g}\right)$ & Density $\left(\mathrm{g} / \mathrm{cm}^{3}\right)$ & $\varepsilon(\%)$ \\
\hline $1.5 \%$-CNC aerogel & 242.88 & 0.7756 & 0.0193 & 98.76 \\
\hline $2.5 \%$-CNC aerogel & 280.36 & 0.6512 & 0.0262 & 98.32 \\
\hline $3.5 \%-C N C$ aerogel & 292.23 & 0.5924 & 0.0352 & 97.74 \\
\hline $1.5 \%-C N F$ aerogel & 296.23 & 0.7196 & 0.0201 & 98.71 \\
\hline $2.5 \%-C N F$ aerogel & 324.36 & 0.6112 & 0.0263 & 98.31 \\
\hline $3.5 \%$-CNF aerogel & 330.88 & 0.5024 & 0.0362 & 97.68 \\
\hline
\end{tabular}

and exponentially after $80 \%$ compressive strain. The deformation of the aerogels at low pressures was mainly attributed to the bending and breaking of hydrogen bonds and physical cross-links (Sehaqui et al. 2010). However, the contact points between nanocellulose molecules in the aerogel increased with an increase in the applied pressure; thus, accelerating the sharp increase in the compression strength.

The compressive stress-strain data of the CNC and CNF aerogels when the compressive strength was higher than $80 \%$ are shown in Fig. $8 \mathrm{c}-\mathrm{e}$. To the best of our knowledge, the contact points between nanofibers in nanocellulose aerogels are mainly produced by hydrogen bond interaction or entanglement, which plays a decisive role in the mechanical properties of the aerogels. The stress values of the $1.5 \%$, $2.5 \%$, and $3.5 \%$-CNF aerogels at $90 \%$ strain were $371.2,680.4$, and $764.3 \mathrm{KPa}$, respectively, and the stress values of the $1.5 \%, 2.5 \%$, and $3.5 \%$-CNC aerogels were $110.9,432.5$, and $521.7 \mathrm{KPa}$, respectively. The compressive strength of the CNF aerogels was higher than that of the CNC aerogels under similar compression conditions, indicating that the CNF aerogels had more contact points. Based on the internal morphology of the aerogels (Fig. 5), the outstanding mechanical properties of the CNF aerogel could be attributed to its excellent structural characteristics. Additionally, with an increase in the mass fraction of nanocellulose, the number of cross-linking points increased, which made the aerogel more compacted; 
thereby, increasing the compressive strength. Particularly, the mechanical properties of the CNC and CNF aerogels prepared by optimal process in this study are better than those of previously reported aerogels (Fig. S4).

\section{Conclusion}

In this study, we isolated two different types of nanocelluloses (CNCs and CNFs) from an eucalyptus pulp, which is commonly used as a raw material industrially, using different treatment methods.

Subsequently, the obtained CNCs and CNFs were used to prepare aerogels using the sol-gel method and supercritical $\mathrm{CO}_{2}$ drying. The characteristics of the $\mathrm{CNC}$ and $\mathrm{CNF}$ aerogels were investigated and compared. The results revealed that the CNCs and CNFs extracted from the pulp exhibited excellent physical and chemical properties, which facilitated the preparation of the high-performance nanocellulose aerogels. CNC and CNF aerogels with a low shrinkage rate (4.55\%) were obtained by controlling the conditions of the drying process. Furthermore, compared to the $\mathrm{CNC}$ aerogels, the CNF aerogels exhibited enhanced pore size distribution, thermal degradation, and physical and mechanical properties. We believe that the findings of this study will provide useful insights for the preparation of nanocellulose-based aerogels. In addition, the strategies presented in this study can be applied to porous nanocellulose aerogels derived from other lignocellulosic biomass; thereby, enhancing the high-value application of biomass materials.

\section{Declarations}

\section{Acknowledgements}

This work was financially supported by the Natural Science Foundation of Jiangsu Province of China (BK20201072), the National Natural Science Foundation of China $(32071687,22108091)$, the National First-class Disciplines (PNFD), the Project Funded by the Priority Academic Program Development of Jiangsu Higher Education Institutions (PAPD), the Postgraduate Research \& Practice Innovation Program of Jiangsu Province (KYCX20_0868), and the Self-made Experimental Teaching Instrument Project of Nanjing Forestry University of 2021 (nlzzyq202113). In addition, this research was supported by the Yonsei University Research Fund of 2021 (2021-22-0034).

\section{References}

1. Ahankari S, Paliwal P, Subhedar A, Kargarzadeh H (2021) Recent Developments in NanocelluloseBased Aerogels in Thermal Applications: A Review. ACSNano 15:3849-3874.

2. Aminah B, Kose R (2019) Properties of Cellulose Nanofibers Prepared from Recycled Pulp Fiber Using the Aqueous Counter Collision Method. J Fiber Sci Technol 75:140-144.

3. Budtova T (2019) Cellulose II aerogels: a review. Cellulose 26:81-121. 
4. Chen WS, Li Q, Wang YC, Yi X, Zeng J, Yu HP et al (2014) Comparative Study of Aerogels Obtained from Differently Prepared Nanocellulose Fibers. ChemSusChem 7:154-161.

5. Chen ZJ, Gao H, Li W, Li SJ, Liu SX, Li J (2020) Research progress of biomass-based optical materials. J For Eng 5:1-12.

6. Dai L, Long Z, Chen J, An XY Cheng D, Khan A et al (2017) Robust Guar Gum/Cellulose Nanofibrils Multilayer Films with Good Barrier Properties. ACS Appl Mater Interfaces 9:5477-5485.

7. De France KJ, Hoare T, Cranston ED (2017) Review of Hydrogels and Aerogels Containing Nanocellulose. Chem Mater 29:4609-4631.

8. Dong H, Ding, QJ, Jiang YF, Li X, Han WJ (2021) Pickering emulsions stabilized by spherical cellulose nanocrystals. Carbohydr Polym 265:118101.

9. Du HS, Liu WM, Zhang ML, Si CL, Zhang XY, Li B (2019) Cellulose nanocrystals and cellulose nanofibrils based hydrogels for biomedical applications. Carbohydr Polym 209:130-144.

10. Gong C, Ni JP, Tian C, Su ZH (2021) Research in porous structure of cellulose aerogel made from cellulose nanofibrils. Int J Biol Macromol 172:573-579.

11. Habibi Y, Lucia LA, Rojas OJ (2010) Cellulose Nanocrystals: Chemistry, Self-Assembly, and Applications. Chem Rev 110:3479-3500.

12. He XH, Chen TT, Jiang TY, Wang C, Luan YH, Liu PT et al (2021) Preparation and adsorption properties of magnetic hydrophobic cellulose aerogels based on refined fibers. Carbohydr Polym 260:117790.

13. Hult EL, Larsson PT, Iversen T (2000) A comparative CP/MAS C-13-NMR study of cellulose structure in spruce wood and kraft pulp. Cellulose 7:35-55.

14. Jiang F, Hsieh YL (2013) Chemically and mechanically isolated nanocellulose and their selfassembled structures. Carbohydr Polym 95:32-40.

15. Jiang S, Zhang ML, Li MM, Liu L, Liu LF, Yu, JY (2020) Cellulose nanofibril (CNF) based aerogels prepared by a facile process and the investigation of thermal insulation performance. Cellulose 27:6217-6233.

16. Kargarzadeh H, Huang J, Lin N, Ahmad I, Mariano M, Dufresne A et al (2018) Recent developments in nanocellulose-based biodegradable polymers, thermoplastic polymers, and porous nanocomposites. Prog Polym Sci 87:197-227.

17. Khan A, Wen YB, Huq T, Ni YH (2018) Cellulosic Nanomaterials in Food and Nutraceutical Applications: A Review. J Agric Food Chem 66:8-19.

18. Kim D, Kim J, Henzie J, Ko Y, Lim H, Kwon G et al (2021). Mesoporous Au films assembled on flexible cellulose nanopaper as high-performance SERS substrates. Chem Eng J 419:129445.

19. Kim D, Ko Y, Kwon G, Choo YM, You J (2018) Low-cost, high-performance plasmonic nanocomposites for hazardous chemical detection using surface enhanced Raman scattering. Sens Actuators B 274:30-36. 
20. Kim D, Ko Y, Kwon G, Kim UJ, Lee JH, You J. (2019) 2,2,6,6-Tetramethylpiperidine-1-oxy-Oxidized Cellulose Nanofiber-Based Nanocomposite Papers for Facile In Situ Surface-Enhanced Raman Scattering Detection. ACS Sustainable Chem Eng 7:15640-15647.

21. Kim SH, Kim JM, Ahn DB, Lee SY (2020) Cellulose Nanofiber/Carbon Nanotube-Based Bicontinuous Ion/Electron Conduction Networks for High-Performance Aqueous Zn-Ion Batteries. Small, $16: 2002837$.

22. Klemm D, Kramer F, Moritz S, Lindstrom T, Ankerfors M, Gray D et al (2011) Nanocelluloses: A New Family of Nature-Based Materials. Angew Chem Int Ed 50:5438-5466.

23. Kwon G, Lee K, Kim D, Jeon Y, Kim UJ, You J (2020) Cellulose nanocrystal-coated TEMPO-oxidized cellulose nanofiber films for high performance all-cellulose nanocomposites. J Hazard Mater 398:123100.

24. Lee K, Jeon Y, Kim D, Kwon G, Kim UJ, Hong C et al (2021) Double-crosslinked cellulose nanofiber based bioplastic films for practical applications. Carbohydr Polym 260:117817.

25. Leung ACW, Hrapovic S, Lam E, Liu YL, Male KB, Mahmoud KA et al (2011) Characteristics and Properties of Carboxylated Cellulose Nanocrystals Prepared from a Novel One-Step Procedure. Small 7:302-305.

26. Li CD, Chen ZF, Dong WF, Lin LL, Zhu XM, Liu QS et al (2021) A review of silicon-based aerogel thermal insulation materials: Performance optimization through composition and microstructure. $J$ Non-Cryst Solids 553:120517.

27. Li Y, Liu XF, Nie XY, Yang WW, Wang YD, Yu RH et al (2019) Multifunctional Organic-Inorganic Hybrid Aerogel for Self-Cleaning, Heat-Insulating, and Highly Efficient Microwave Absorbing Material. Adv Funct Mater 29:1807624.

28. Li YL, Liu YS, Liu Y, Lai WC, Huang F, Ou AP et al (2018) Ester Crosslinking Enhanced Hydrophilic Cellulose Nanofibrils Aerogel. ACS Sustainable Chem Eng 6:11979-11988.

29. Liu S, Zhang Y, Jiang $\mathrm{H}$, Wang $X Y$, Zhang TM, Yao $Y(2018)$ High $\mathrm{CO}_{2}$ adsorption by amino-modified bio-spherical cellulose nanofibres aerogels. Environ Chem Lett 16:605-614.

30. Lu ZH, An XY, Zhang H, Liu LQ, Dai HQ, Cao HB et al (2020) Cationic cellulose nano-fibers (CCNF) as versatile flocculants of wood pulp for high wet web performance. Carbohydr Polym 229:115434.

31. Lv D, Du HS, Che XP, Wu MY, Zhang YD, Liu C et al (2019) Tailored and Integrated Production of Functional Cellulose Nanocrystals and Cellulose Nanofibrils via Sustainable Formic Acid Hydrolysis: Kinetic Study and Characterization. ACS Sustainable Chem Eng 7:9449-9463.

32. Mautner A (2020) Nanocellulose water treatment membranes and filters: a review. Polym Int 69: 741751.

33. Nagarajan KJ, Ramanujam NR, Sanjay MR, Siengchin S, Rajan BS, Basha KS et al (2021) A comprehensive review on cellulose nanocrystals and cellulose nanofibers: Pretreatment, preparation, and characterization. Polym Compos 42:1588-1630. 
34. Nishiyama $Y$, Wada $M$, Hanson BL, Langan $P$ (2010) Time-resolved X-ray diffraction microprobe studies of the conversion of cellulose I to ethylenediamine-cellulose I. Cellulose 17:735-745.

35. Oh SY, Yoo DI, Shin Y, Seo G (2005) FTIR analysis of cellulose treated with sodium hydroxide and carbon dioxide. Carbohydr Res 340:417-428.

36. Pierre AC, Pajonk GM (2002) Chemistry of aerogels and their applications. Chem Rev 102:4243-4265.

37. Rol F, Belgacem MN, Gandini A, Bras J (2019) Recent advances in surface-modified cellulose nanofibrils. Prog Polym Sci 88:241-264.

38. Sehaqui H, Salajkova M, Zhou Q, Berglund LA (2010) Mechanical performance tailoring of tough ultra-high porosity foams prepared from cellulose I nanofiber suspensions. Soft Matter 6:1824-1832.

39. Shamskar KR, Heidari H, Rashidi A (2019) Study on Nanocellulose Properties Processed Using Different Methods and Their Aerogels. J Polym Environ 27:1418-1428.

40. Shang QQ, Chen JQ, Yang XH, Liu CG, Hu Y, Zhou YH (2019) Fabrication and oil absorbency of superhydrophobic magnetic cellulose aerogels. J For Eng 4:105-111.

41. Song SW, Kim D, Kim J, You JM, Kim HM (2021) Flexible nanocellulose-based SERS substrates for fast analysis of hazardous materials by spiral scanning. J Hazard Mater 414:125160.

42. Sun B, Zhang M, Hou QX, Liu R, Wu T, Si CL (2016) Further characterization of cellulose nanocrystal (CNC) preparation from sulfuric acid hydrolysis of cotton fibers. Cellulose 23:439-450.

43. Sun XX, Li MC, Ren SX, Lei TZ, Lee SY, Lee SY et al (2020) Zeolitic imidazolate framework-cellulose nanofiber hybrid membrane as Li-lon battery separator: Basic membrane property and battery performance. J Power Sources 454:227878.

44. Sun Y, Chu YL, Wu WB, Xiao HN (2021) Nanocellulose-based lightweight porous materials: A review. Carbohydr Polym 255:117489.

45. Thomas B, Raj MC, Athira KB, Rubiyah MH, Joy J, Moores A et al (2018) Nanocellulose, a Versatile Green Platform: From Biosources to Materials and Their Applications. Chem Rev 118:11575-11625.

46. Tran VH, Kim JD, Kim JH, Kim SK, Lee JM (2020) Influence of Cellulose Nanocrystal on the Cryogenic Mechanical Behavior and Thermal Conductivity of Polyurethane Composite. J Polym Environ 28:1169-79.

47. Wan CC, Jiao Y, Wei S, Zhang LY, Wu YQ, Li J (2019) Functional nanocomposites from sustainable regenerated cellulose aerogels: A review. Chem Eng J 359:459-475.

48. Wang CH, Kim J, Tang J, Na J, Kang YM, Kim M et al (2020). Large-Scale Synthesis of MOF-Derived Superporous Carbon Aerogels with Extraordinary Adsorption Capacity for Organic Solvents. Angew Chem Int Ed 59:2066-2070.

49. Wang Z, Zhu WK, Huang RZ, Zhang Y, Jia C, Zhao H et al (2020). Fabrication and Characterization of Cellulose Nanofiber Aerogels Prepared via Two Different Drying Techniques. Polym 12:2583.

50. Wei S, Ching YC, Chuah CH (2020) Synthesis of chitosan aerogels as promising carriers for drug delivery: A review. Carbohydr Polym 231:115744. 
51. Xu XZ, Liu F, Jiang L, Zhu JY, Haagenson D, Wiesenborn DP (2013) Cellulose Nanocrystals vs. Cellulose Nanofibrils: A Comparative Study on Their Microstructures and Effects as Polymer Reinforcing Agents. ACS Appl Mater Interfaces 5:2999-3009.

52. Xu WW, Liu CZ, Wu QL, Xie WW, Kim WY, Lee SY et al (2020) A stretchable solid-state zinc ion battery based on a cellulose nanofiber-polyacrylamide hydrogel electrolyte and a $\mathrm{Mg}_{0.23} \mathrm{~V}_{2} \mathrm{O}_{5} \cdot 1 \cdot 0 \mathrm{H}_{2} \mathrm{O}$ cathode. J Mater Chem A 8:18327-18337.

53. Zhao GM, Du J, Chen WM, Pan MZ, Chen DY (2019) Preparation and thermostability of cellulose nanocrystals and nanofibrils from two sources of biomass: rice straw and poplar wood. Cellulose 26:8625-8643.

54. Zhang TM, Zhang Y, Jiang H, Liu S, Yao Y (2018) Characterization of CNF/CNC composite aerogel. J For Eng 3:91-96.

55. Zhang TM, Zhang Y, Wang XY, Liu S, Yao Y (2018) Characterization of the nano-cellulose aerogel from mixing CNF and CNC with different ratio. Mater Lett 229:103-106.

56. Zhu WK, Ji MX, Chen FQ, Wang Z, Chen W, Xue YY et al (2020) Formaldehyde-free resin impregnated paper reinforced with cellulose nanocrystal (CNC): Formulation and property analysis. J Appl Polym Sci 137:48931.

57. Zhu WK, Ji MX, Zhang Y, Wang Z, Chen W, Xue YY (2019) Synthesis and Characterization of Aminosilane Grafted Cellulose Nanocrystal Modified Formaldehyde-Free Decorative Paper and its $\mathrm{CO}_{2}$ Adsorption Capacity. Polym 11:2021.

58. Zhu WK, Yao Y, Zhang Y, Jiang H, Wang Z, Chen W et al (2020). Preparation of an Amine-Modified Cellulose Nanocrystal Aerogel by Chemical Vapor Deposition and Its Application in $\mathrm{CO}_{2}$ Capture. Ind Eng Chem Res 59:16660-16668.

\section{Figures}




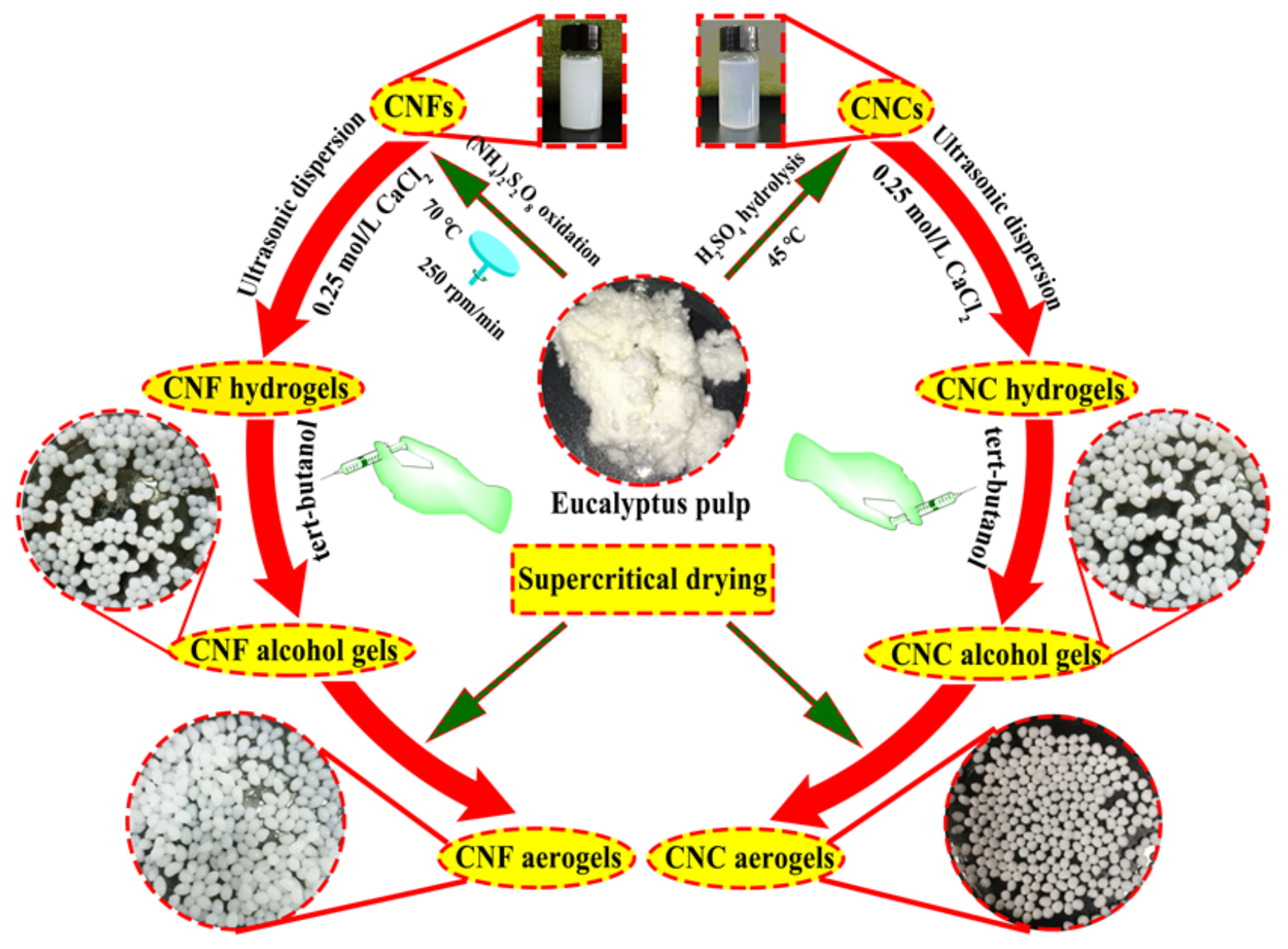

Figure 1

Schematic illustration of the preparation of cellulose nanocrystal (CNC) and cellulose nanofibers (CNF) aerogels using the same raw material. 

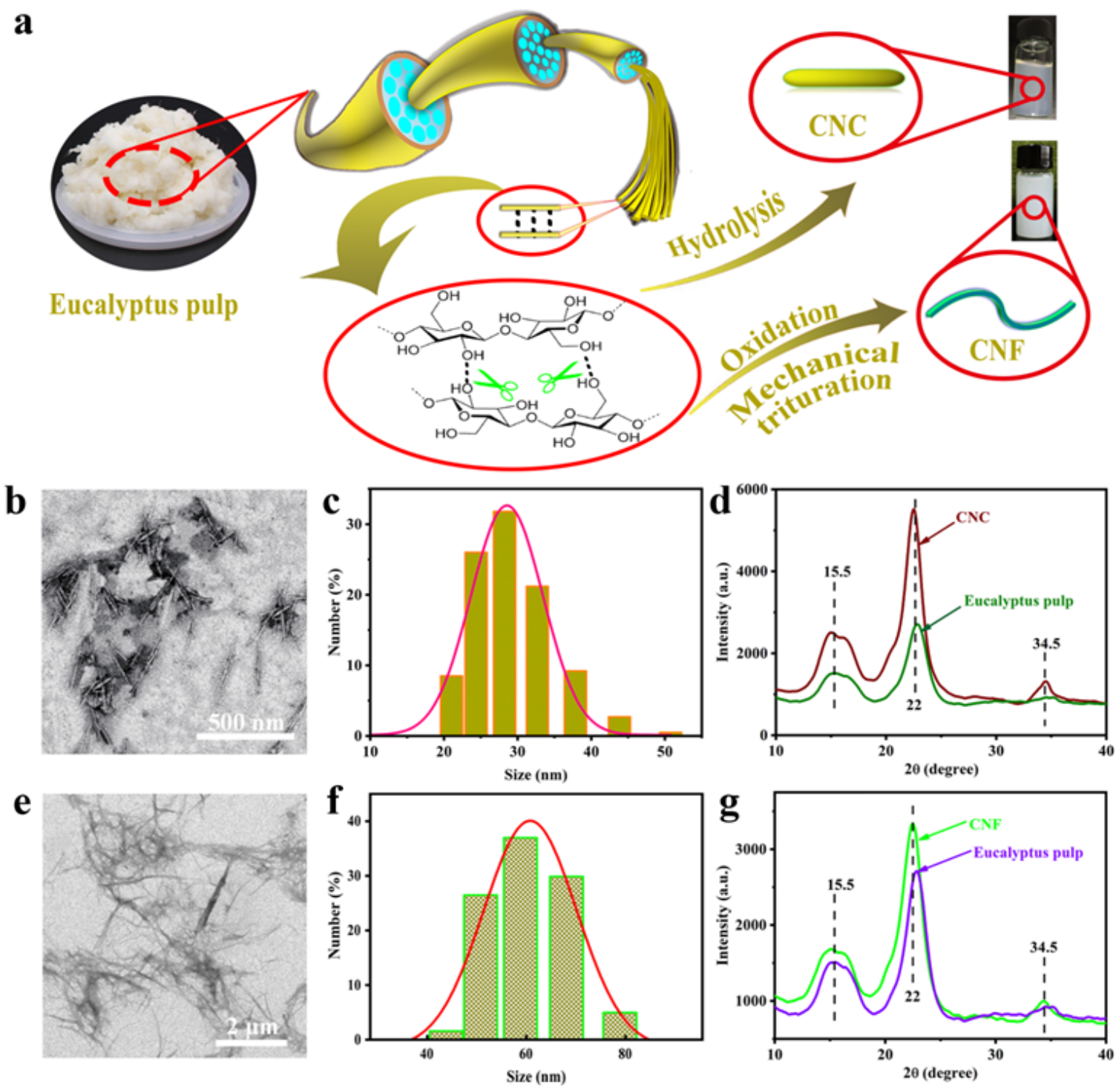

\section{Figure 2}

Physical properties characterization of the CNCs and CNFs solution. (a) Schematic illustration of the fabrication of CNCs and CNFs from eucalyptus pulp. (b) Transmission electron microscopy (TEM) image, (c) size distribution, and (d) X-ray diffraction (XRD) patterns of the CNCs. (e) TEM image, (f) size distribution, and (g) XRD patterns of the CNFs. 

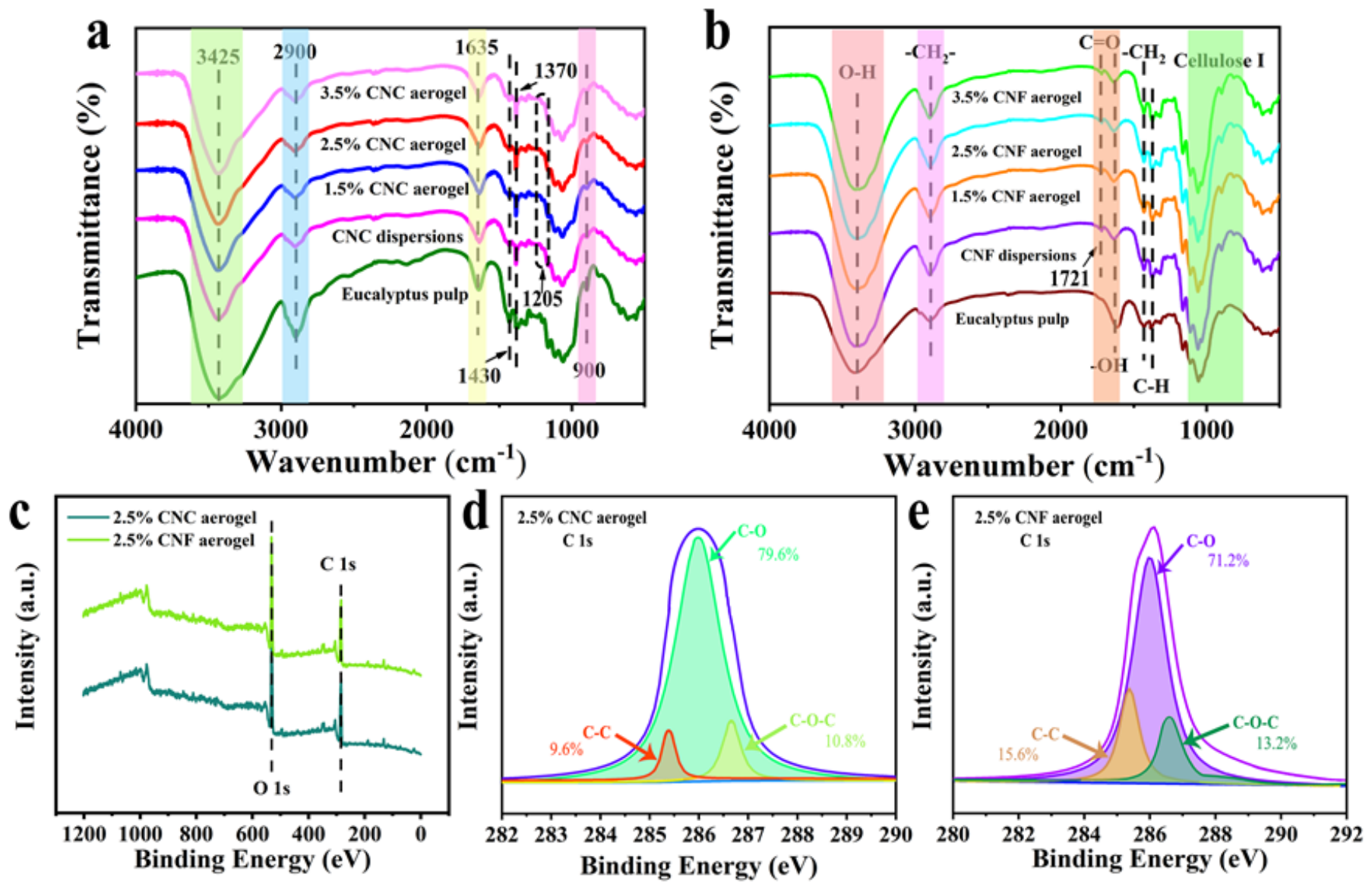

Figure 3

Chemical structure and chemical composition of the pulp and nanocellulose aerogels with different contents. Fourier transform infrared (FT-IR) spectra of (a) CNC aerogels and (b) CNF aerogels with different mass fractions. (c) X-ray photoelectron spectroscopy (XPS) profile of $2.5 \%$-CNC and $2.5 \%$-CNF aerogels. High-resolution C $1 \mathrm{~s}$ spectra of the (d) $2.5 \%-\mathrm{CNC}$ and (e) $2.5 \%-\mathrm{CNF}$ aerogels. 
a

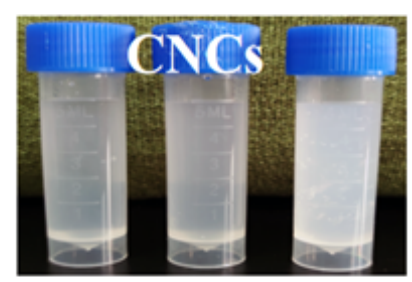

$1.5 w t \% 2.5$ wt $\% 3.5 w t \%$

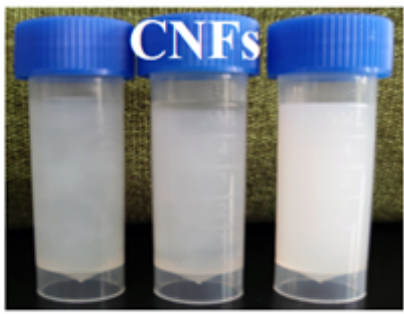

1.5 wt $\% 2.5$ wt $\% 3.5$ wt $\%$

C
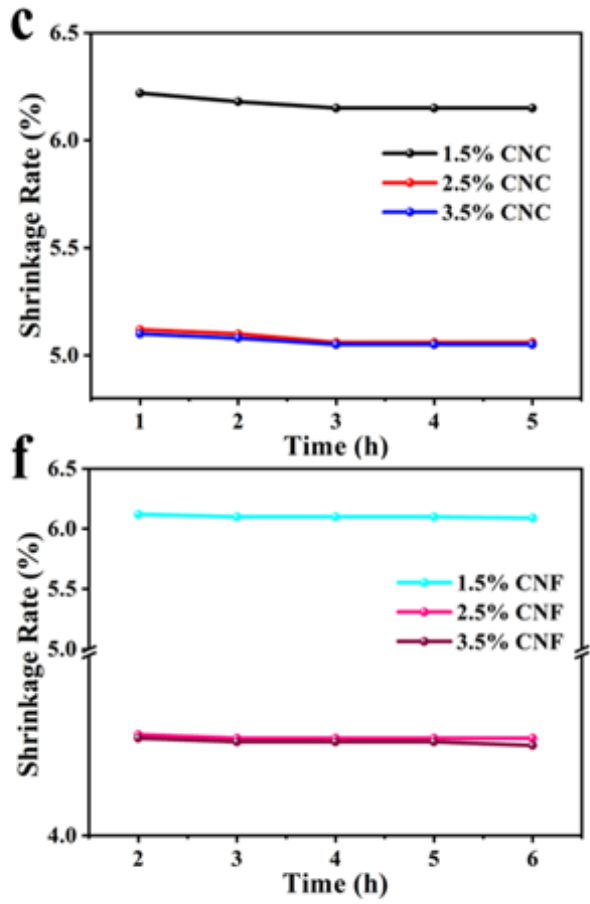

b

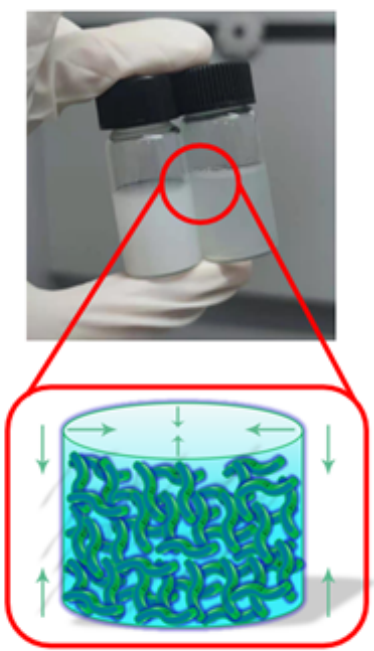

Nanocellulose hydrogels
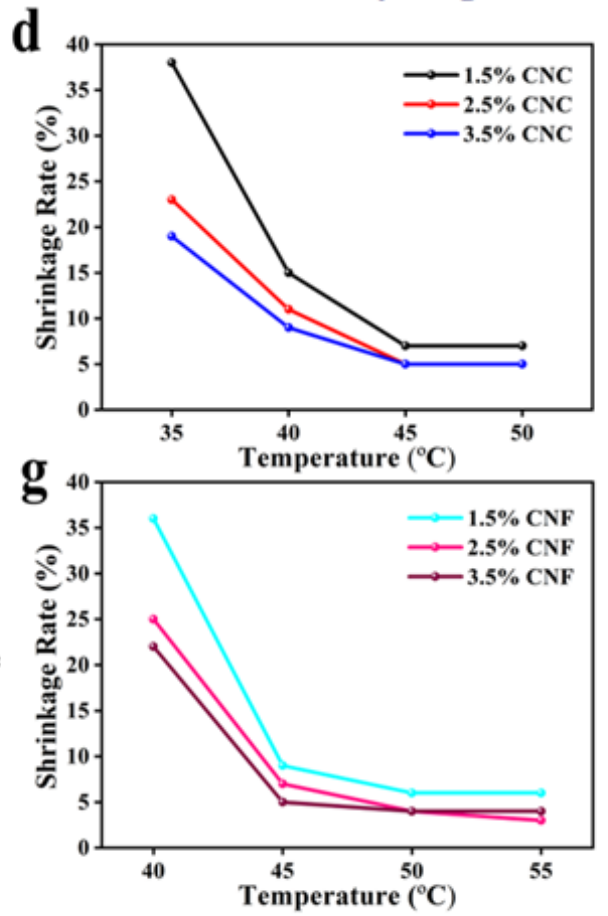

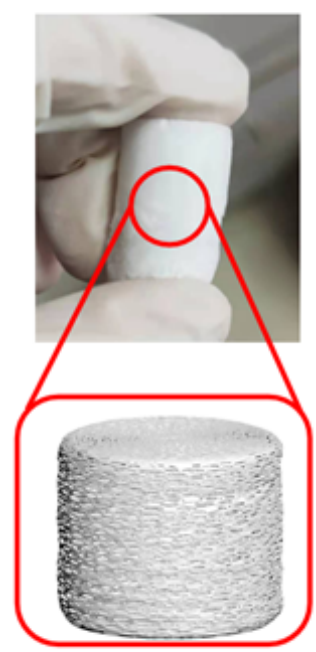

Nanocellulose aerogels
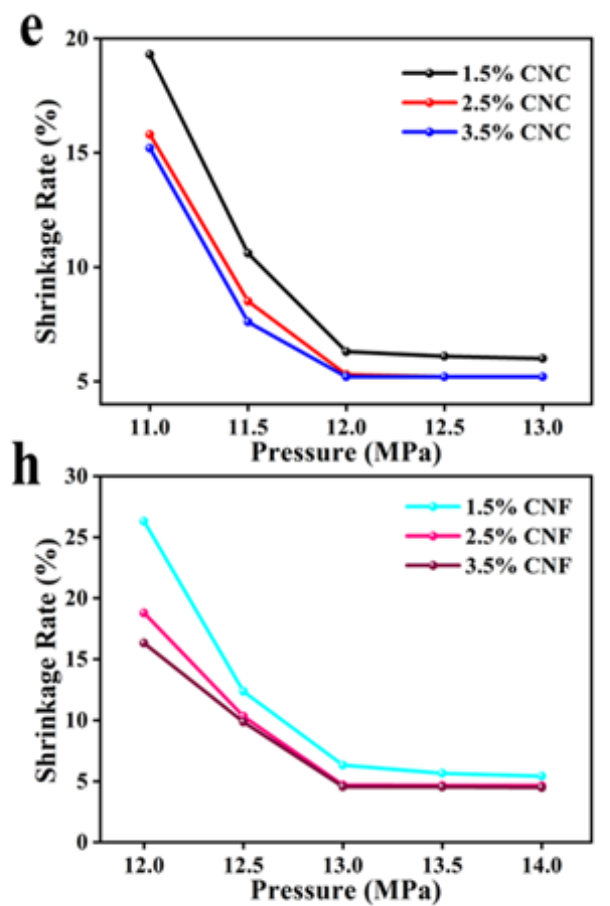

Figure 4

(a) Dispersion state of the CNC and CNF aqueous suspensions. (b) Schematic of the shrinkage process of the nanocellulose aerogels. Effect of the (c) drying time, (d) temperature and (e) pressure of the supercritical $\mathrm{CO} 2$ drying on the shrinkage rate of the $\mathrm{CNC}$ aerogels. Effect of the $(\mathrm{f})$ drying time, $(\mathrm{g})$ temperature ( $h$ ) and pressure of the supercritical $\mathrm{CO} 2$ drying on the shrinkage rate of the CNF aerogels. 

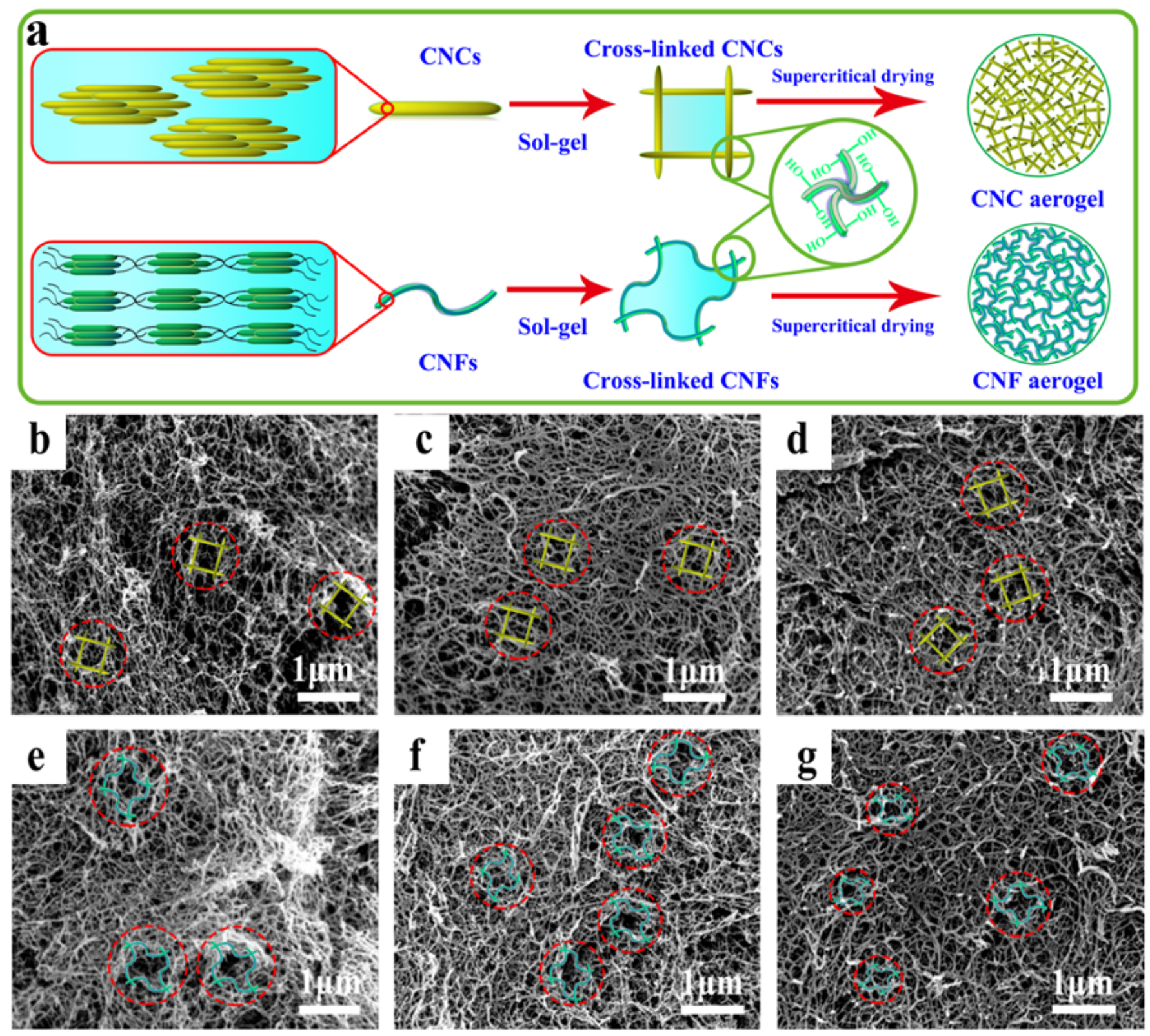

Figure 5

(a) Schematic of the cross-linking of the CNC and CNF aerogels. Scanning electron microscopy (SEM) images of the (b) $1.5 \%-C N C$, (c) $2.5 \%-C N C$, (d) $3.5 \%-C N C$, (e) $1.5 \%-C N F$, (f) $2.5 \%-C N F$, and (g) $3.5 \%-C N F$ aerogels. 

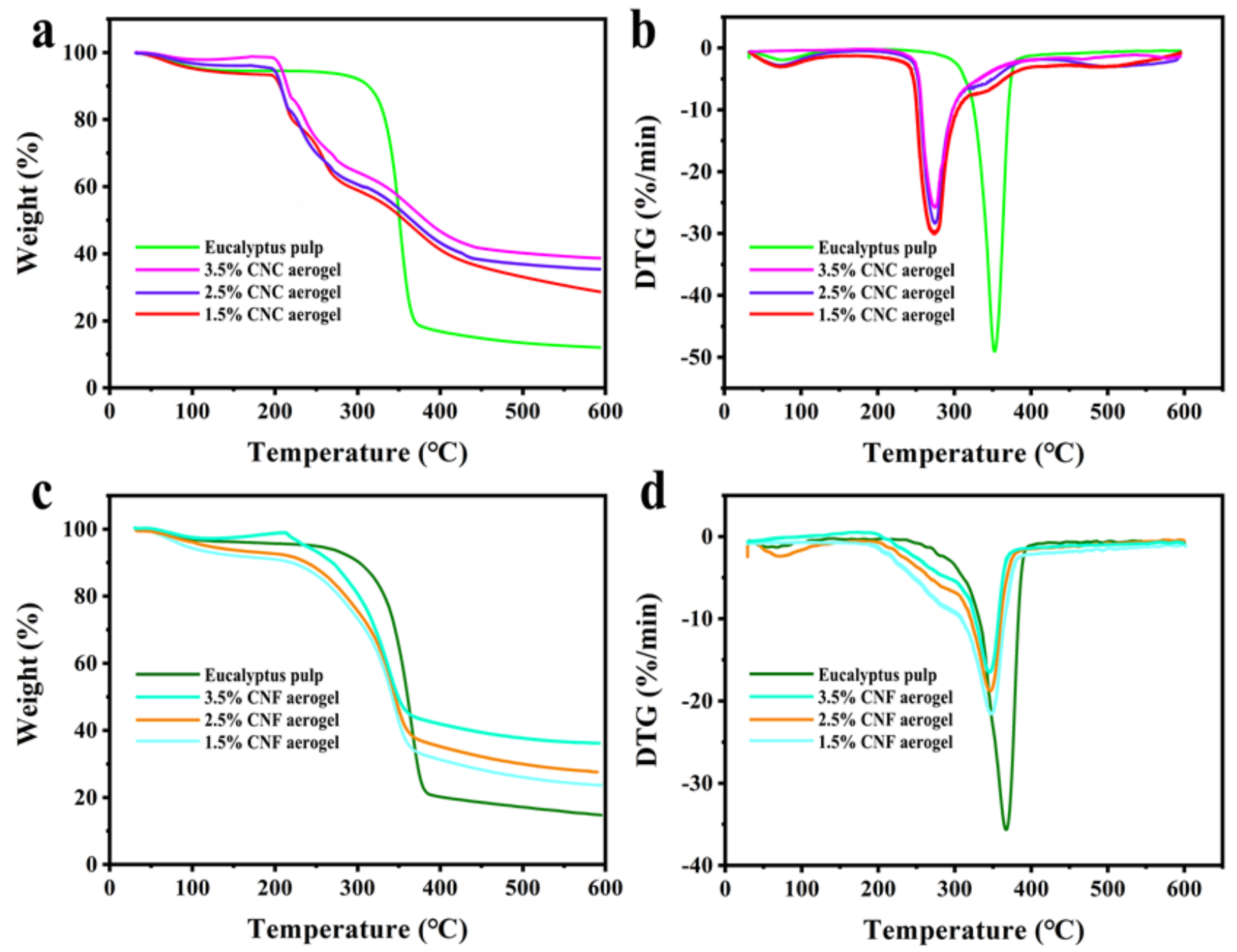

Figure 6

Thermogravimetric analysis (TGA) result of the raw material, CNC, and CNF aerogels. (a and c) TGA and (b and d) differential thermogravimetric (DTG) curves of the eucalyptus pulp, CNC, and CNF aerogels at different concentrations. 

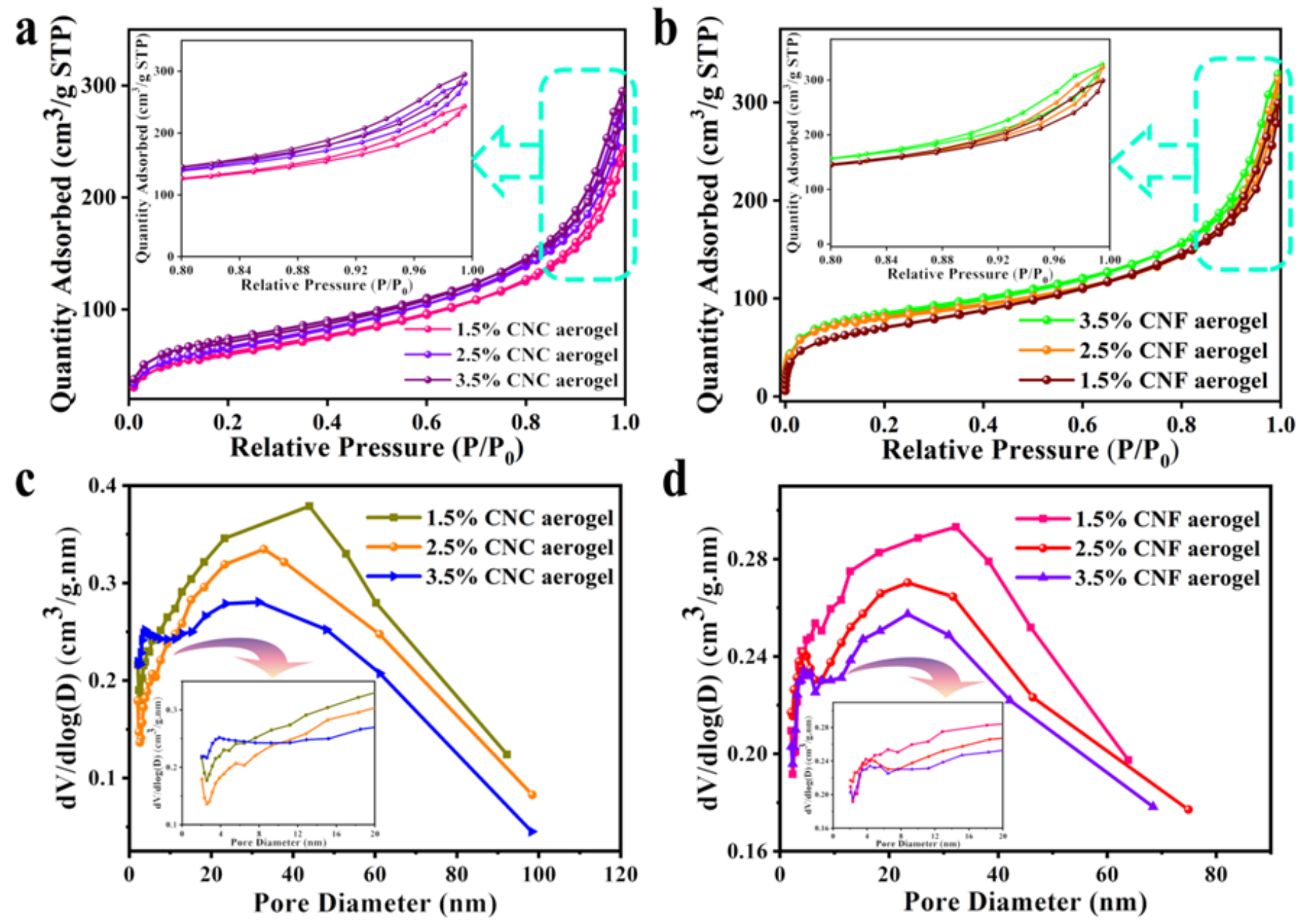

Figure 7

N2 adsorption-desorption isotherms at $77 \mathrm{~K}$ of the (a) CNC and (b) CNF aerogels after the supercritical $\mathrm{CO} 2$ drying process. Pore size distributions of the (c) CNC and (d) CNF aerogels with different concentrations. 

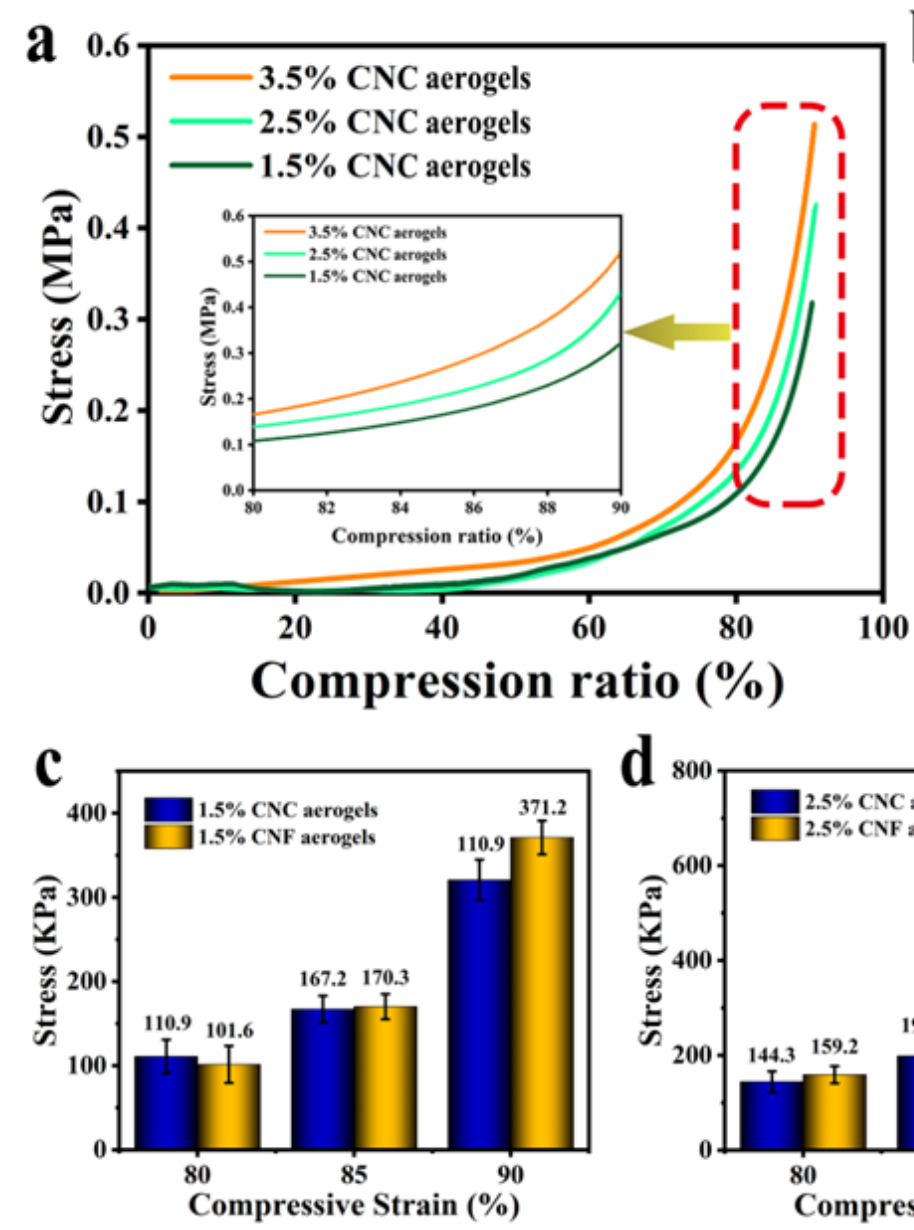
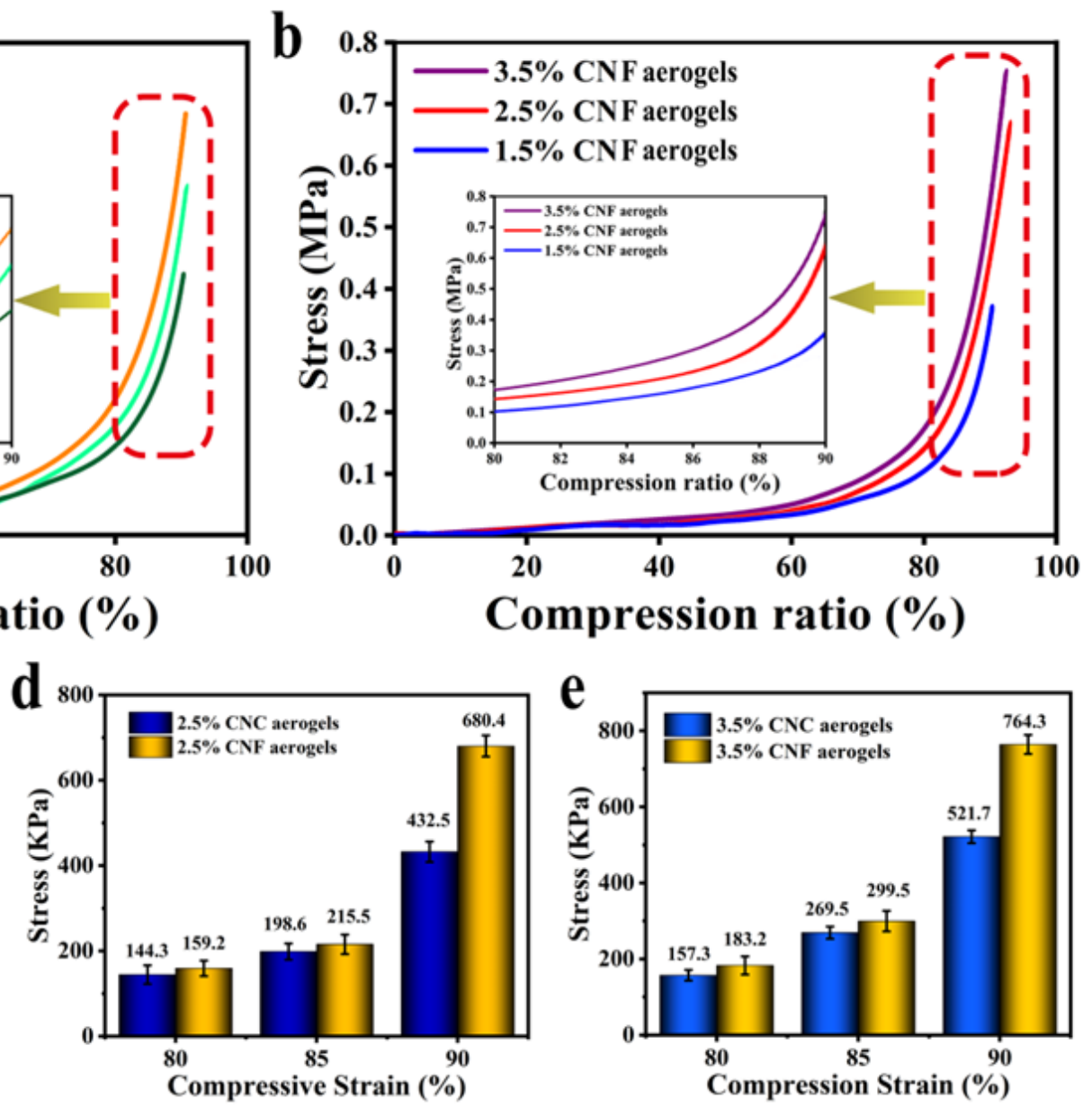

Figure 8

$(a-b)$ Compressive stress-strain curves and (c-e) histogram of the stress contrast of the CNC and CNF aerogels at different strains.

\section{Supplementary Files}

This is a list of supplementary files associated with this preprint. Click to download.

- Graphicalabstract.doc

- SupportingInformation.doc 